\title{
Preparation and characterization of poly(stearyl methacrylate) grafted natural rubber in latex stage Nurul Hayati Yusof ${ }^{1,2}$, Kenichiro Kosugi ${ }^{1}$, Tan Kim Song ${ }^{2}$, Seiichi Kawahara ${ }^{1}$, ${ }^{1}$ Department of Materials Science and Technology, Faculty of Engineering, Nagaoka University of Technology, Nagaoka, Niigata 940-2188, Japan \\ Tel.:81-258-47-9301; Fax: 81-258-47-9300; corresponding e-mail: kawahara@mst.nagaokaut.ac.jp \\ ${ }^{2}$ Malaysian Rubber Board, RRIM Research Station, Sg. Buloh, 47000 Selangor, Malaysia
}

\begin{abstract}
An attempt to prepare graft copolymer of natural rubber, NR and poly(stearyl methacrylate), PSMA, was made to improve mechanical properties of NR, since the grafted PSMA was composed of crystallizable stearyl groups as a nucleating agent and methacrylate units. The graft-copolymerization of stearyl methacrylate (SMA) onto deproteinized natural rubber (DPNR) was performed in latex stage with tert-butylhydroperoxide (TBHPO) / tetraethylenepentamine (TEPA) as an initiator, after purifying the rubber with urea and sodium dodecyl sulfate followed by centrifugation. The optimal conditions for the graft-copolymerization were determined as follows: $3.3 \times 10^{-2} \mathrm{~mol} / \mathrm{kg}$-rubber of initiator, $1.5 \mathrm{~mol} / \mathrm{kg}$-rubber of monomer and $30 \mathrm{w} / \mathrm{w} \%$ of dry rubber content (DRC). The conversion and grafting efficiency of SMA were $95 \mathrm{~mol} \%$ and 60 mol\%, respectively. After graft-copolymerization, the melting temperature of PSMA increased from $304.1 \mathrm{~K}$ to $306.2 \mathrm{~K}$. The morphology showed that the DPNR particles, which were about 1 $\mu \mathrm{m}$ in average diameter, were well dispersed in PSMA nanomatrix. The stress at break increased about three times, i.e. $13 \mathrm{MPa}$, as high as that of DPNR. The increase in the mechanical properties was promoted by the nucleating effect of stearyl group of PSMA.
\end{abstract}

Keywords:

Natural rubber, poly(stearyl methacrylate), latex stage, nanomatrix structure, nucleating agent, mechanical properties

\section{Introduction}

Saturated fatty acid such as stearic acid is well known to play an important role as a nucleating agent in the crystallization of polymers. For instance, the crystallization of cis-1,4polyisoprene is markedly promoted by the saturated fatty acid, since lattice mismatch between the saturated fatty acid and the cis-1,4-polyisoprene is very small on the basis of the same 
crystallography, i.e. orthorhombic [1-3]. A good pair of crystal planes is 001 plane of natural rubber (NR) and 110 plane of stearic acid: that is, 0.889 and $1.246 \mathrm{~nm}$ for NR [3] and 0.89 and $1.25 \mathrm{~nm}(0.25 \mathrm{~nm} \times 5)$ for stearic acid [4]. However, the nucleating effect of fatty acid on the strain-induced crystallization is considered to be small due to the fringed micelle structure of the strain-induced crystal. Therefore, it is necessary to prove the nucleating effect of fatty acid on the strain-induced crystallization of cis-1,4-polyisoprene, since it may be the origin of the outstanding mechanical properties of the polymer.

The nucleating effect of fatty acid on the strain-induced crystallization is quite difficult to investigate, since the strain-induced crystallization occurs too rapidly [5-6]; that is, the nucleating effect is negligibly small. Therefore, an elaborate study is required to prove the nucleating effect on the strain-induced crystallization. In previous works, the effect of fatty acid on the strain-induced crystallization of NR in droplets, which were dispersed in styrenebutadiene rubber (SBR), was investigated, since the crystallization of the rubber was significantly suppressed in the droplets [7]. The tear energy was measured by the changing temperature and tear rate, and it was related to the strain-induced crystallization. The tear energy decreased after the removal of fatty acid [8], whereas it recovered to the original level after stearic acid was added to the rubber [9-11]. However, little nucleating effect was found in the strain-induced crystallization of synthetic cis-1,4-polyisoprene (IR). The difference in the nucleating effect between NR and IR may be attributed to the presence of the linked fatty acid of NR, which was reported in previous papers [12].

The chemical linkage between fatty acid and cis-1,4-polyisoprene, i.e. NR, may be formed by the graft-copolymerization of a suitable monomer, such as stearyl methacrylate (SMA) onto the rubber; that is, the stearyl groups may gather to form crystallites, and 
polymethacrylate may link the crystallized stearyl groups to NR. The graft copolymerization must be carried out in the latex stage, since the stearyl groups are required to cover the NR particles, as reported in previous papers, whereby phospholipids and proteins are ensured to cover the NR particles [13]. In this case, it is necessary to achieve a high grafting efficiency to prepare the NR model in order to investigate the nucleating effect of the crystallized stearyl group on the strain-induced crystallization and the mechanical properties of NR.

There have been a few studies on the graft-copolymerization of stearyl methacrylate onto NR in solution. For instance, the graft-copolymerization of various alkylmethacrylates was performed in a toluene solution of NR and IR, respectively [14-15]. The grafting efficiency of SMA, in this case, was reported to be about $40 \mathrm{~mol} \%$. The low grafting efficiency was explained to be due to a chain transfer of radicals in the solution [16]. The grafting efficiency remained unimproved, even though the graft-copolymerization of SMA was carried out in the presence of divinylbenzene in toluene and chloroform solutions of the rubber [17]. Thus, in order to enhance the grafting efficiency, it is necessary to change the nature of the solution from hydrophobic to hydrophilic. However, no attempt has been made to perform the graft-copolymerization of SMA onto NR in water.

The strategy to prepare the NR model may be concerned with the method to increase the grafting efficiency of SMA in latex stage. It is necessary at least to remove the proteins from NR, since the proteins are known to be a radical scavenger. According to the previous work, high grafting efficiency was achieved for graft-copolymerization of vinyl monomers on NR when using purified latex, i.e. deproteinized natural rubber (DPNR) latex as a starting material instead of HANR latex [22]. A novel technique was developed to purify the NR in latex stage; that is, the proteins were removed from the $\mathrm{NR}$, using urea as a denaturant in the presence of sodium 
dodecyl sulfate (SDS) [18-19]. After the removal of the proteins, the graft-copolymerization of SMA onto NR may be performed with an organic redox initiator in latex stage. In the previous work, a high conversion and high grafting efficiency were achieved under the optimal condition for the graft-copolymerization of styrene [20-21], methyl methacrylate [22], acrylonitrile [23], vinyltriethoxysilane [24-25] and so forth. The nanomatrix structure was formed in the resulting products, as in the case of NR. Therefore, the NR model may be prepared from NR through the graft-copolymerization of SMA in latex stage with an organic redox initiator.

In the present study, an attempt was made to prepare the NR model by the graftcopolymerization of SMA onto DPNR in latex stage in the presence of tert-butylhydroperoxide (TBHP)/tetraethlenepentamine (TEPA) as an organic redox initiator. The factors influencing the graft-copolymerization of SMA were investigated to determine the optimal conditions: for instance, the dry rubber content (DRC), the initiator concentration and monomer concentration. The resulting polymers were then characterized by particle size analysis, Fourier transform infrared (FT-IR) spectroscopy, and differential scanning calorimetry (DSC). The mechanical properties, such as tensile strength was measured to confirm the effect of the crystallized stearyl groups on the strain-induced crystallization of the NR model.

\section{Materials and Methods}

\subsection{Materials}

High ammonia natural rubber (HANR) latex was purchased from Golden Hope Plantation, Malaysia. The SDS surfactant, TBHP - 68\% and TEPA were from Kishida Chemicals (Japan) while the urea, potassium persulfate (KPS) and benzoyl peroxide (BPO) were from Nacalai Tesque (Japan). The SMA monomer was from Tokyo Kasei Company (Japan). The 
$\alpha, \alpha^{\prime}$-azobisisobutyronitrile (AIBN) was from Kanto Chemical Co. Inc. (Japan). The solvents used, such as acetone, tetrahydrofuran (THF), methanol, and toluene were from Nacalai Tesque (Japan).

\subsection{Removal of proteins from NR latex}

The HANR latex was diluted with distilled water from 60 to $30 \mathrm{w} / \mathrm{w} \%$ of dry rubber content (DRC). The removal of the proteins from the NR was carried out by the incubation of the latex with $0.1 \mathrm{w} / \mathrm{w} \%$ urea in the presence of $1 \mathrm{w} / \mathrm{w} \%$ SDS at $303 \mathrm{~K}$. The latex was then, centrifuged (ca, 10,000 g) 3-times at $288 \mathrm{~K}$ for 30 minutes. The cream fraction was collected after the second and third centrifugation and was re-dispersed in the solution with $0.5 \mathrm{w} / \mathrm{w} \%$ SDS and $0.1 \mathrm{w} / \mathrm{w} \%$ SDS, respectively. The procedure to remove the proteins is shown in Figure 1. Prior to the graft-copolymerization, the DRC and the amount of SDS in the DPNR latex were adjusted to $30 \mathrm{w} / \mathrm{w} \%$ and $0.1 \mathrm{w} / \mathrm{w} \%$, respectively.

\subsection{Preparation of graft-copolymer}

The graft-copolymerization of SMA onto DPNR was carried out in latex stage using various initiators. DPNR latex of 200 grams with $20 \mathrm{w} / \mathrm{w} \%$ DRC and $0.5 \mathrm{w} / \mathrm{w} \%$ SDS was purged with $\mathrm{N}_{2}$ gas for 1 hour. Then, the initiator and SMA were added in turn to the latex. The graftcopolymerization was performed for 8 hours with continuous stirring at $200 \mathrm{rpm}$ under $\mathrm{N}_{2}$ atmosphere at $333 \mathrm{~K}$ in a water bath. The un-reacted SMA was removed with a rotary evaporator under reduced pressure for about 30 minutes at $353 \mathrm{~K}$. The reacted latex was poured into a petri dish and dried in an oven at $323 \mathrm{~K}$ for about 2 days (until dry) and in a vacuum oven for 3 days at $323 \mathrm{~K}$. The reacted rubber was subjected to Soxhlet extraction under nitrogen atmosphere in the dark for 24 hours to remove homopolymer. The grafted rubber was obtained after the extraction and dried at $323 \mathrm{~K}$. Then, the grafted rubber was characterized accordingly. The 
procedure for the graft-copolymerization is shown in Figure 2. The conditions for the graftcopolymerization of SMA onto DPNR in latex stage are shown in Table 1.

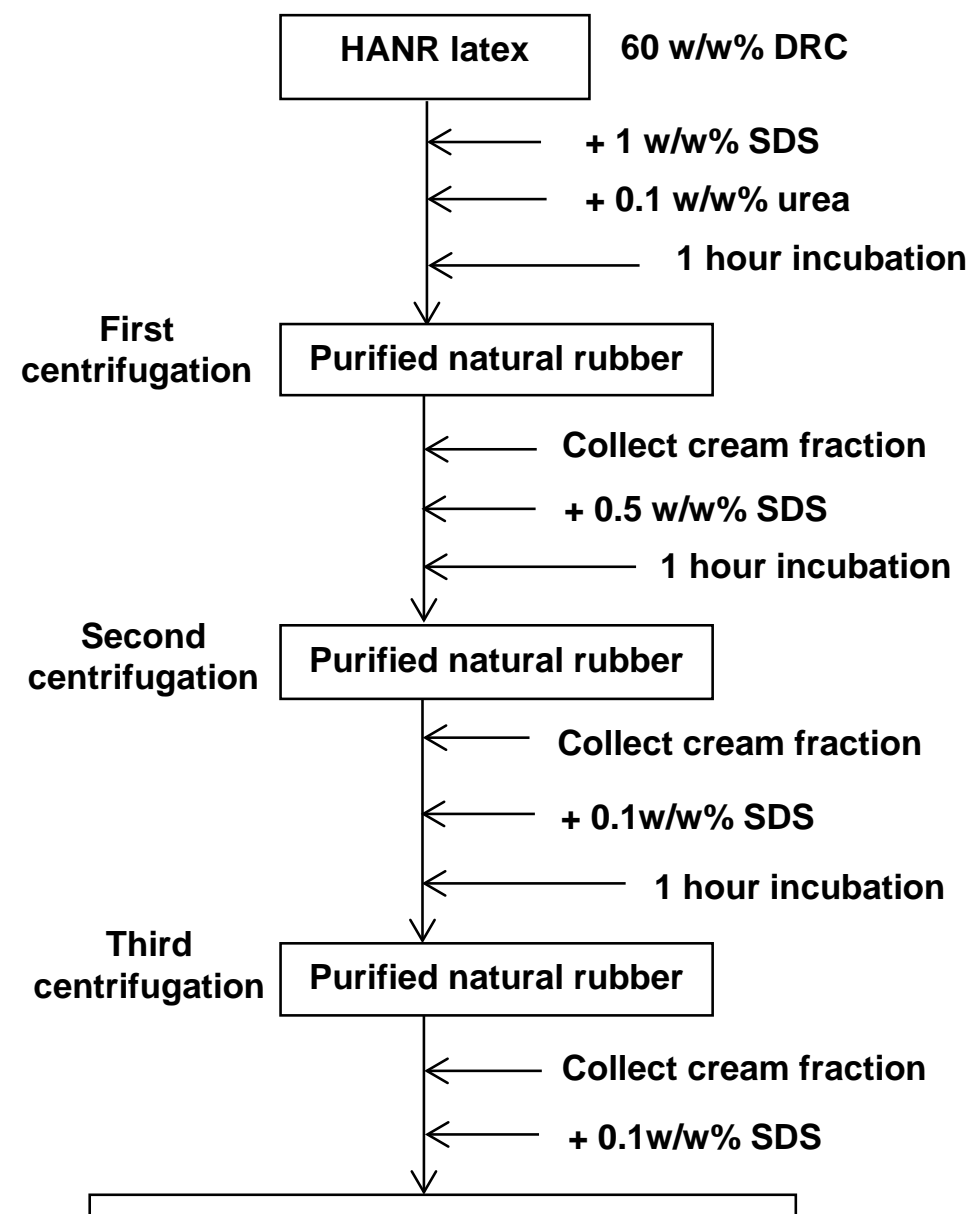

$\begin{array}{ll}\text { Deproteinized natural rubber (DPNR) } & 30 \text { w/w\% DRC }\end{array}$

Figure 1: Removal of proteins from NR latex 


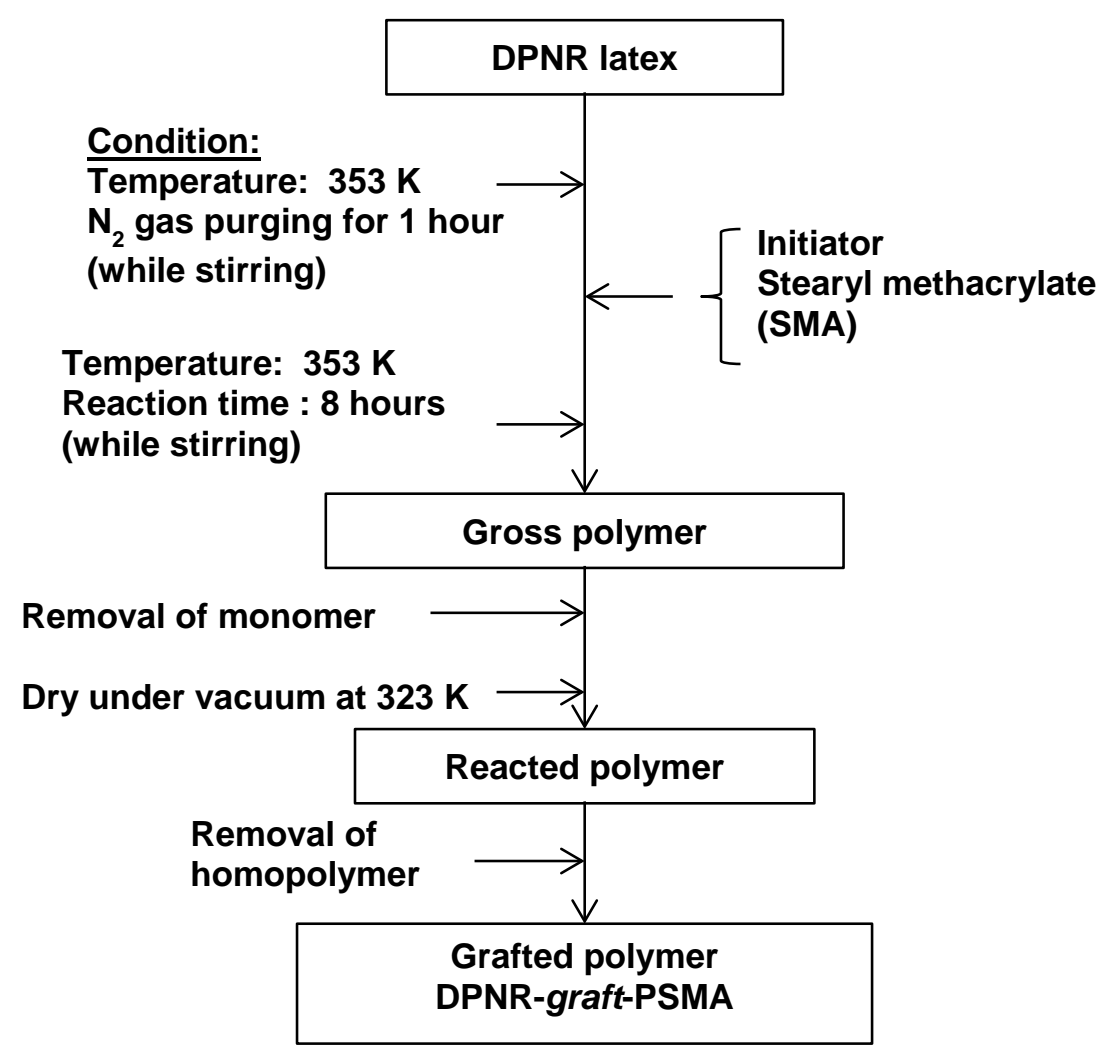

Figure 2: Procedure of graft-copolymerization of SMA onto DPNR in latex stage

\subsection{Particle size measurement}

The particle size distribution of the rubber latex was determined by the COULTER LS230. The particles sizes, ranging between 0.04 to $2000 \mu \mathrm{m}$ were recorded.

\subsection{Differential Scanning Calorimetry (DSC)}

The DSC measurements were performed with a SII SSC/5200 DSC 220 at a heating rate of $10 \mathrm{~K} / \mathrm{min}$ at a temperature, ranging between $153 \mathrm{~K}$ and $353 \mathrm{~K}$. About $10 \mathrm{mg}$ of the rubber specimens were encapsulated in an aluminium pan. The glass transition temperature, $T_{g}$, was determined as an inflection point of the tangential line of the DSC at which a sudden drop in the heat capacity took place. The melting temperature, $T_{m}$, was determined as a peak top point, at which the endothermic peak appeared due to melting. 
Table 1: Conditions of the graft-copolymerization of SMA onto DPNR in latex stage

\begin{tabular}{|c|c|c|c|c|c|c|}
\hline $\begin{array}{c}\text { Sample } \\
\text { name }\end{array}$ & $\begin{array}{c}\text { DRC } \\
\text { (w/w\%) }\end{array}$ & Initiator system & $\begin{array}{l}\text { Initiator } \\
\text { (mol/kg- } \\
\text { rubber) }\end{array}$ & $\begin{array}{l}\text { Monomer } \\
\text { (mol/kg- } \\
\text { rubber) }\end{array}$ & $\begin{array}{l}\text { Reaction } \\
\text { time } \\
\text { (hour) }\end{array}$ & $\begin{array}{c}\text { Reaction } \\
\text { temperature } \\
\text { (K) }\end{array}$ \\
\hline KPS-6.6-0.5 & 30 & KPS & $6.6 \times 10^{-2}$ & 0.5 & 8 & 333 \\
\hline TВHР/TEPA-6.6-0.5 & 30 & TBHP/TEPA & $6.6 \times 10^{-2}$ & 0.5 & 8 & 333 \\
\hline BPO-6.6-0.5 & 30 & $\mathrm{BPO}$ & $6.6 \times 10^{-2}$ & 0.5 & 8 & 333 \\
\hline AIBN-6.6-0.5 & 30 & AIBN & $6.6 \times 10^{-2}$ & 0.5 & 8 & 333 \\
\hline DRC10-6.6-1.0 & 10 & TBHP/TEPA & $6.6 \times 10^{-2}$ & 1.0 & 8 & 333 \\
\hline DRC20-6.6-1.0 & 20 & TBHP/TEPA & $6.6 \times 10^{-2}$ & 1.0 & 8 & 333 \\
\hline DRC30-6.6-1.0 & 30 & TBHP/TEPA & $6.6 \times 10^{-2}$ & 1.0 & 8 & 333 \\
\hline DRC30-3.3-1.0 & 30 & TBHP/TEPA & $3.3 \times 10^{-2}$ & 1.0 & 8 & 333 \\
\hline DPNR-graft-PSMA-0.25 & 30 & TBHP/TEPA & $3.3 \times 10^{-2}$ & 0.25 & 8 & 333 \\
\hline DPNR-graft-PSMA-0.5 & 30 & TBHP/TEPA & $3.3 \times 10^{-2}$ & 0.5 & 8 & 333 \\
\hline DPNR-graft-PSMA-0.75 & 30 & TBHP/TEPA & $3.3 \times 10^{-2}$ & 0.75 & 8 & 333 \\
\hline DPNR-graft-PSMA-1.0 & 30 & TBHP/TEPA & $3.3 \times 10^{-2}$ & 1.0 & 8 & 333 \\
\hline DPNR-graft-PSMA-1.5 & 30 & TВHР/TEPA & $3.3 \times 10^{-2}$ & 1.5 & 8 & 333 \\
\hline DPNR-graft-PSMA-2.0 & 30 & TBHP/TEPA & $3.3 \times 10^{-2}$ & 2.0 & 8 & 333 \\
\hline
\end{tabular}




\subsection{Fourier transform infra-red (FT-IR) measurement}

The functional group of the graft-copolymer was verified by FT-IR spectroscopy. The FT-IR spectra were recorded with a JASCO FT-IR 410 spectrometer in the range of $4000-400 \mathrm{~cm}^{-1}$ at a

resolution of $4 \mathrm{~cm}^{-1}$. Two calibration curves were obtained for (1) a series of mixtures of poly(stearylmethacrylate) (PSMA) and DPNR, and (2) a series of mixtures of methyl stearate and synthetic cis-1,4-polyisoprene (IR). The overall SMA content and fatty acid ester content $\left(\mathrm{C}=\mathrm{O}_{\text {TотAL }}\right)$ is calculated based on the intensity ratios of peak at $1664 \mathrm{~cm}^{-1}(\mathrm{C}=\mathrm{C})$ and overlapped peak at $1732 \mathrm{~cm}^{-1}(\mathrm{C}=\mathrm{O})$ using calibration curve (1). The fatty acid ester content (DPNR only) is calculated based on intensity peak at $1664 \mathrm{~cm}^{-1}(\mathrm{C}=\mathrm{C})$ and $1740 \mathrm{~cm}^{-1}(\mathrm{C}=\mathrm{C})$ using calibration curve (2). Then, the amount of SMA content is normalized by subtracting the fatty acid ester content (estimated using calibration curve (2)) from the overall SMA content and fatty acid ester content (estimated using calibration curve (1)).

\subsection{Tensile properties measurement}

The tensile properties were measured according to JIS K6251. The film samples, with a thickness of about $1 \mathrm{~mm}$ were cut with a Dumbell-shaped Type 7. The test piece was stretched at a crosshead speed of $200 \mathrm{~mm} / \mathrm{min}$. The data of the stress and strain of the sample were plotted in a stress-strain curve.

\subsection{Transmission electron microscopy observations}

The morphology at high magnification was observed by a transmission electron microscope (TEM), FEI TECNAI G2 at an accelerating voltage of $200 \mathrm{kV}$. Ultra-thin sections of the sample 
were prepared by a Leica UC7 at $183 \mathrm{~K}$, and then the sections were placed onto the copper grid before being subjected to the electron beam of the TEM. The samples were stained with 2 w/w\% osmium tetroxide solution for 3 hours.

\subsection{Results and discussion}

3.1 Graft-copolymerization of SMA

\subsubsection{Effect of initiator system}

Table 2: Effect of initiator system on graft-copolymerization of SMA

\begin{tabular}{|c|c|c|c|c|c|c|c|}
\hline \multirow[b]{2}{*}{ Sample name } & & & & \multirow[b]{2}{*}{$\begin{array}{c}\text { Temp } \\
(\mathrm{K})\end{array}$} & \multicolumn{3}{|c|}{ SMA } \\
\hline & $\begin{array}{l}\text { Initiator } \\
\text { (mol/kg- } \\
\text { rubber) }\end{array}$ & $\begin{array}{c}\text { Monomer } \\
\text { (mol/kg- } \\
\text { rubber) }\end{array}$ & $\begin{array}{l}\text { DRC of } \\
\text { latex } \\
\text { (w/w\%) }\end{array}$ & & $\begin{array}{l}\text { Reaction } \\
\text { time } \\
\text { (hour) }\end{array}$ & $\begin{array}{c}\text { unit } \\
\text { content } \\
\text { (mol\%) }\end{array}$ & $\begin{array}{l}\text { Conversion } \\
\text { (mol\%) }\end{array}$ \\
\hline KPS-6.6-0.5 & $6.6 \times 10^{-2}$ & 0.5 & 30 & 333 & 8 & 1.86 & 55.51 \\
\hline TВHP/TEPA-6.6-0.5 & $6.6 \times 10^{-2}$ & 0.5 & 30 & 333 & 8 & 2.91 & 80.56 \\
\hline ВРО-6.6-0.5 & $6.6 \times 10^{-2}$ & 0.5 & 30 & 333 & 8 & 0.89 & 26.37 \\
\hline AIBN-6.6-0.5 & $6.6 \times 10^{-2}$ & 0.5 & 30 & 333 & 8 & 0.56 & 32.80 \\
\hline
\end{tabular}

Table 2 shows the effect of the initiator system on the graft-copolymerization of SMA onto DPNR in the latex stage, whereby the SMA unit content and conversion were estimated by the following equations (1) and (2):

SMA unit content $($ mol $\%)=\frac{(\text { Mole of SMA units in gross polymer })}{(\text { Mole of cis-1,4-isoprene units })+(\text { Mole of SMA units })} \times 100$

Conversion $($ mol\% $)=\frac{(\text { Mole of SMA units in gross polymer })}{(\text { Mole of SMA feed })} \times 100$ 
The SMA unit content and conversion were dependent upon the initiator system. They were the highest when TBHP/TEPA-6.6-0.5 was used as an initiator. The SMA unit content and conversion decreased with TBHP/TEPA-6.6-0.5, KPS-6.6-0.5, BPO-6.6-0.5 and AIBN-6.6-0.5 in that order. The SMA unit content and the conversion may reflect the reactivity of the initiators in the latex stage. The highest SMA unit content and conversion may be explained to be due to (1) a suitable life time of organic redox initiator, i.e. TBHPO/TEPA-6.6-0.5 at the polymerization temperature of 333K [16, 34-35] and (2) TBHPO/TEPA may have an advantage to form the active sites between the rubber and the aqueous interface [26-27]. In the subsequent study, the TBHP/TEPA was used as an initiator for the graft-copolymerization of SMA onto DPNR in latex stage.

\subsubsection{Effect of dry rubber content (DRC) and initiator concentrations}

Table 3 shows the effects of the DRC and the initiator concentration on the graftcopolymerization of SMA onto DPNR. The SMA unit content and conversion of SMA were dependent upon the DRC and initiator concentration. The SMA unit content increased as the DRC increased, and it increased further as the initiator concentration decreased. The SMA unit content increased as the DRC was increased, which implies that the SMA unit content is dependent on the amount of rubber particles per volume of latex. When less rubber particles per volume, i.e. $10 \mathrm{w} / \mathrm{w} \%$, react with high initiator concentration, i.e. 6.6 x $10^{-2} \mathrm{~mol} / \mathrm{kg}$-rubber, chain transfer and side reaction may occur due to the formation of excessive radicals. Hence, low SMA unit content and conversion may be obtained. When the DRC increased, more rubber particles per volume may proportionally react with the initiator resulted in high SMA unit content and conversion. The SMA unit content increased further when initiator concentration decreased, suggests that the rubber particles per volume of latex, i.e. $30 \mathrm{w} / \mathrm{w} \% \mathrm{DRC}$ may react efficiently 
with the initiator concentration of $3.3 \times 10^{-2} \mathrm{~mol} / \mathrm{kg}$-rubber. More radicals may form and cause the chain transfer and side reaction at high initiator concentration, i.e. $6.6 \times 10^{-2} \mathrm{~mol} / \mathrm{kg}$-rubber, which resulted in the low SMA unit content and conversion. In previous studies, a suitable initiator concentration, DRC and monomer concentration were found for various monomers, i.e. styrene [20-21], methylmethacrylate [22], acrylonitrile [23] and vinyltriethoxysilane [24-25]. This implies that the SMA unit content and the conversion may be the highest at a suitable initiator concentration, DRC and monomer concentration. In the present study, the suitable initiator concentration and DRC were determined to be $3.3 \times 10^{-2} \mathrm{~mol} / \mathrm{kg}$-rubber and $30 \mathrm{w} / \mathrm{w} \%$, respectively.

Table 3: Effects of DRC and initiator concentration on graft-copolymerization of SMA

\begin{tabular}{|c|c|c|c|c|c|c|c|}
\hline \multirow[b]{2}{*}{ Sample name } & \multirow[b]{2}{*}{$\begin{array}{l}\text { Initiator } \\
\text { (mol/kg- } \\
\text { rubber) }\end{array}$} & \multirow[b]{2}{*}{$\begin{array}{l}\text { Monomer } \\
\text { (mol/kg- } \\
\text { rubber) }\end{array}$} & \multirow[b]{2}{*}{$\begin{array}{l}\text { DRC of } \\
\text { latex } \\
\text { (w/w\%) }\end{array}$} & \multirow[b]{2}{*}{$\begin{array}{c}\text { Temp } \\
(\mathrm{K})\end{array}$} & \multirow[b]{2}{*}{$\begin{array}{c}\text { Reaction } \\
\text { time } \\
\text { (hour) }\end{array}$} & \multirow[b]{2}{*}{$\begin{array}{c}\text { SMA } \\
\text { unit } \\
\text { content } \\
\text { (mol\%) }\end{array}$} & \multirow[b]{2}{*}{$\begin{array}{c}\text { Conversion } \\
\text { (mol\%) }\end{array}$} \\
\hline & & & & & & & \\
\hline DRC10-6.6-1.0 & $6.6 \times 10^{-2}$ & 1.0 & 10 & 333 & 8 & 1.27 & 18.86 \\
\hline DRC20-6.6-1.0 & $6.6 \times 10^{-2}$ & 1.0 & 20 & 333 & 8 & 2.79 & 42.16 \\
\hline DRC30-6.6-1.0 & $6.6 \times 10^{-2}$ & 1.0 & 30 & 333 & 8 & 4.56 & 70.12 \\
\hline DRC30-3.3-1.0 & $3.3 \times 10^{-2}$ & 1.0 & 30 & 333 & 8 & 5.00 & 77.22 \\
\hline
\end{tabular}




\subsubsection{Effect of monomer concentration}

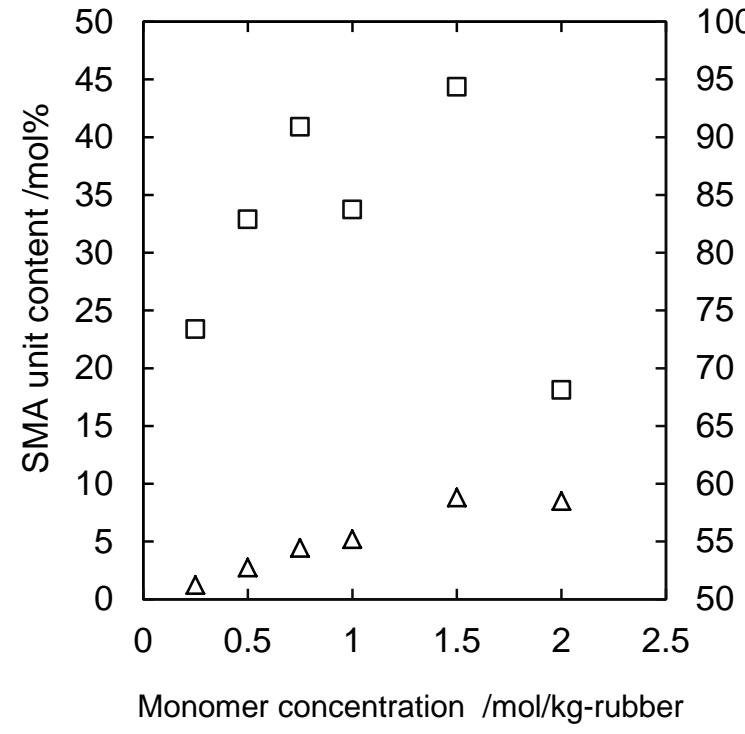

(a)

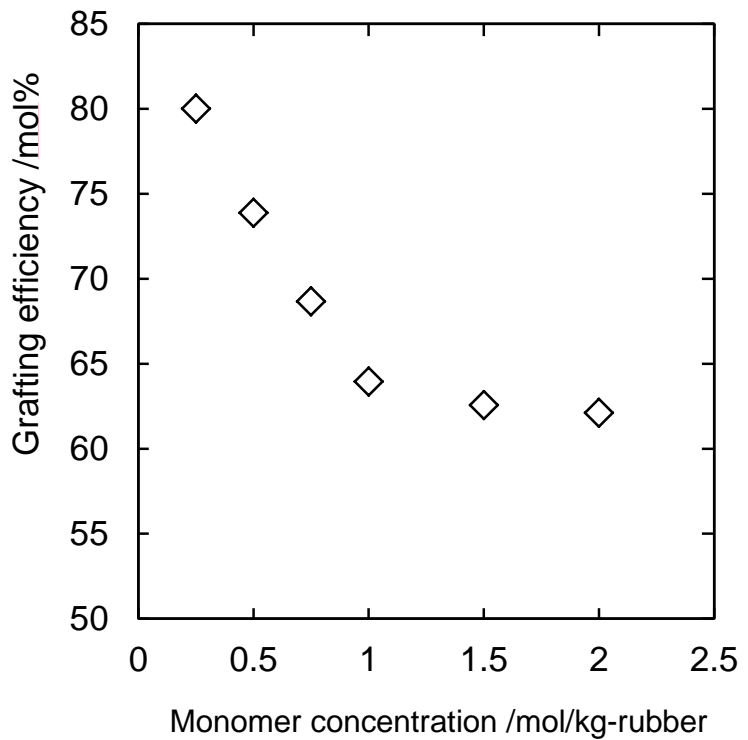

(b)

Figure 3: Effect of monomer concentration on graft-copolymerization of SMA (a) Monomer content $(\triangle)$ and conversion $(\square)$ and (b) grafting efficiency, $(\diamond)$ of SMA ranging from 0.25 to

\section{$2.0 \mathrm{~mol} / \mathrm{kg}$-rubber}

Figure 3 shows the effect of monomer concentrations, ranging from 0.25 to $2.0 \mathrm{~mol} / \mathrm{kg}$ rubber, on SMA unit content, conversion and grafting efficiency of the graft-copolymerization of SMA. The grafting efficiency of SMA is estimated by the following equation (3):

$$
\text { Grafting efficiency }(\text { mol } \%)=\frac{\text { Mole of SMA units linked to cis }-1,4-\text { polyisoprene }}{\text { Mole of SMA units produced during graft }- \text { copolymerization }} \times 100
$$

Figure 3(a) shows that the monomer content increased monotonically as the monomer concentration increased; the higher the monomer concentration, the higher the SMA unit content. On the other hand, the conversion increased to its maximum value, i.e. $95 \mathrm{~mol} \%$ at $1.5 \mathrm{~mol} / \mathrm{kg}-$ rubber feed of SMA, and then it decreased as the SMA concentration increased. The increase in the SMA unit content may be related to the increase in the monomer concentration. In contrast, 
the decrease in the conversion at a low SMA concentration may be explained to be due to the reduced probability of encountering the SMA with the active sites on the NR particles, whereas the decrease at a high SMA concentration may be due to the excess amount of SMA, which resulted in unreacted SMA. Thus, a suitable SMA concentration was determined to be 1.5 $\mathrm{mol} / \mathrm{kg}$-rubber.

The grafting efficiency decreased as the monomer concentration increased, and it remained unchanged when the SMA concentration was higher than $1.0 \mathrm{~mol} / \mathrm{kg}$-rubber, as shown in Figure 3(b). The highest grafting efficiency was $80 \mathrm{~mol} \%$ at $0.25 \mathrm{~mol} / \mathrm{kg}$-rubber SMA, and it decreased to $62 \mathrm{~mol} \%$ at $1.0 \mathrm{~mol} / \mathrm{kg}$-rubber SMA. The decrease in the grafting efficiency implies that the homopolymerization of SMA occurs dominantly rather than the graft-copolymerization of SMA onto the surface of the NR particles. Consequently, a suitable SMA concentration was determined to be $1.5 \mathrm{~mol} / \mathrm{kg}$-rubber at $3.3 \times 10^{-2} \mathrm{~mol} / \mathrm{kg}$-rubber initiator, i.e. DPNR-graftPSMA-1.5.

\subsection{Particle size distribution}

Figure 4 shows the particle size distribution for DPNR, DPNR-graft-PSMA-0.25, DPNRgraft-PSMA-0.5, DPNR-graft-PSMA-1.5 and DPNR-graft-PSMA-2.0. The bimodal distribution was found for NR, i.e. DPNR, as in the case of the previous literature [28]. After the graftcopolymerization of SMA, the particle size distribution became multimodal, except for the DPNR-graft-PSMA-0.25. The shoulder peak at about $0.6 \mu \mathrm{m}$ appeared in the major peak in the large particle region for the DPNR-graft-PSMA-0.5, DPNR-graft-PSMA-1.5 and DPNR-graftPSMA-2.0, whereas it did not appear for the DPNR-graft-PSMA-0.25. The appearance of the shoulder peak implies that new particles are formed during the graft-copolymerization. This may 
be explained to be due to the formation of the SMA homopolymer, which corresponds with the decrease in the grafting efficiency at high monomer concentrations, as shown in Figure 3(b).

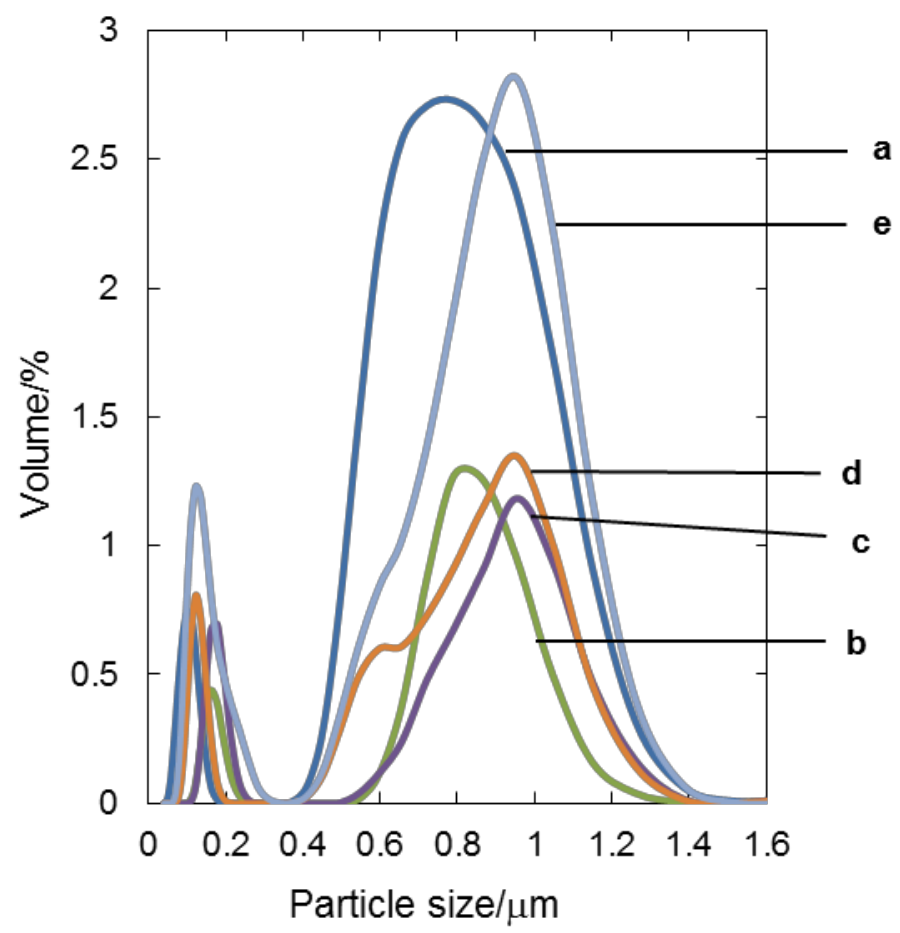

Figure 4: Particle size distribution of (a) DPNR, (b) DPNR-graft-PSMA-0.25, (c) DPNR-graftPSMA-0.5, (d) DPNR-graft-PSMA-1.5 and (e) DPNR-graft-PSMA-2.0

\subsection{Fourier transform infra-red (FT-IR) spectroscopy}

The FT-IR spectra for DPNR, PSMA, and DPNR-graft-PSMA-1.5, ranging from 1600 to $1800 \mathrm{~cm}^{-1}$ are shown in Figure 5. For DPNR, the absorption peaks appeared at $1740 \mathrm{~cm}^{-1}$ and $1664 \mathrm{~cm}^{-1}$, which were identified as the stretching vibrations of the ester $(\mathrm{C}=\mathrm{O})$ group of fatty acid esters and the stretching vibrations of the carbon-carbon double bond $(\mathrm{C}=\mathrm{C})$ of the cis-1,4isoprene units, respectively. For PSMA, the absorption peak appeared at $1730 \mathrm{~cm}^{-1}$, which was identified as the stretching vibrations of the ester $(\mathrm{C}=\mathrm{O})$ group of PSMA [29]. After the graftcopolymerization, two overlapping absorption peaks appeared at $1732 \mathrm{~cm}^{-1}$ and $1740 \mathrm{~cm}^{-1}$, and 
one absorption peak appeared at $1664 \mathrm{~cm}^{-1}$, respectively, for the DPNR-graft-PSMA-1.5. The overlapping peaks at 1732 and $1740 \mathrm{~cm}^{-1}$ may be identified as the peaks of the stretching vibrations of the ester $(\mathrm{C}=\mathrm{O})$ group of the PSMA and the fatty acid ester, respectively.

In order to determine the SMA unit content of DPNR-graft-PSMA, a calibration line was made in a plot of the ratio of the overlapping peaks at $1732 \mathrm{~cm}^{-1}$ (represented by $\mathrm{C}=\mathrm{O}_{\text {TOTAL}}$ ) and $1740 \mathrm{~cm}^{-1}$ (represented by $\mathrm{C}=\mathrm{O}_{\mathrm{NR}}$ ) to the peak at $1664 \mathrm{~cm}^{-1}$ versus the SMA unit content for PSMA and DPNR, respectively. The estimated SMA unit content for the DPNR-graft-PSMAs is tabulated in Table 5. The SMA unit content was dependent upon the monomer (SMA) concentration, except for the DPNR-graft-PSMA-0.25. The SMA unit content of the DPNRgraft-PSMA-0.25 was quite high compared to that of the DPNR-graft-PSMA-0.5 and DPNRgraft-PSMA-0.75, which was consistent with the grafting efficiency shown in Figure 3. The calculated SMA unit content is used as the weight fraction, $W(\mathrm{w} / \mathrm{w})$ of PSMA in the DPNR for the determination of the degree of crystallinity.

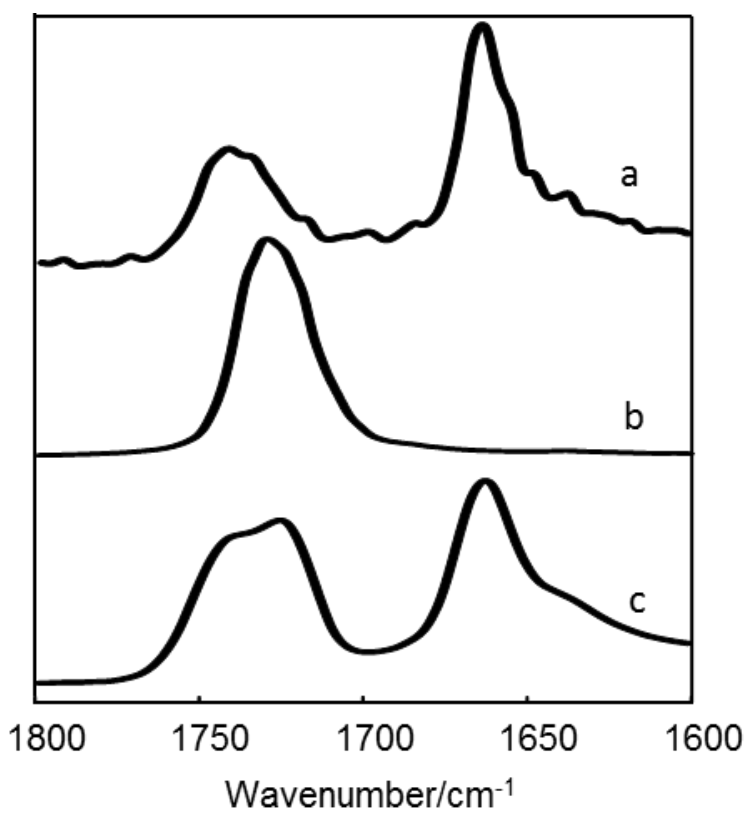


Figure 5: FT-IR spectra for (a) DPNR, (b) PSMA and (c) DPNR-graft-PSMA-3.3-1.5

Table 4: The total of fatty acid ester content of DPNR and PSMA content ( $\mathrm{C}=\mathrm{O}_{\text {TOTAL }}$ ), fatty acid ester content of DPNR ( $\left.\mathrm{C}=\mathrm{O}_{\mathrm{NR}}\right)$ and PSMA content, measured against the FT-IR calibration curves

\begin{tabular}{lccc}
\hline Sample name & $\begin{array}{c}\mathrm{C}=\mathrm{O}_{\text {TOTAL }} \\
(\mathrm{mmol} / \mathrm{kg}- \\
\text { rubber })\end{array}$ & $\begin{array}{c}\mathrm{C}=\mathrm{O}_{\mathrm{NR}} \\
(\mathrm{mmol} / \mathrm{kg}- \\
\text { rubber })\end{array}$ & $\begin{array}{c}\text { PSMA } \\
\text { content } \\
\text { (grafted } \\
\text { PSMA) } \\
(\mathrm{mmol} / \mathrm{kg}- \\
\text { rubber })\end{array}$ \\
\hline DPNR & - & 27 & - \\
DPNR-graft-PSMA-0.25 & 125.92 & - & 98.92 \\
DPNR-graft-PSMA-0.5 & 80.93 & - & 53.93 \\
DPNR-graft-PSMA-0.75 & 75.99 & - & 48.99 \\
DPNR-graft-PSMA-1.0 & 144.28 & - & 117.28 \\
DPNR-graft-PSMA-1.5 & 221.37 & - & 194.37 \\
DPNR-graft-PSMA-2.0 & 246.89 & - & 219.89 \\
\hline
\end{tabular}




\subsection{Differential scanning calorimetry (DSC) thermograms}

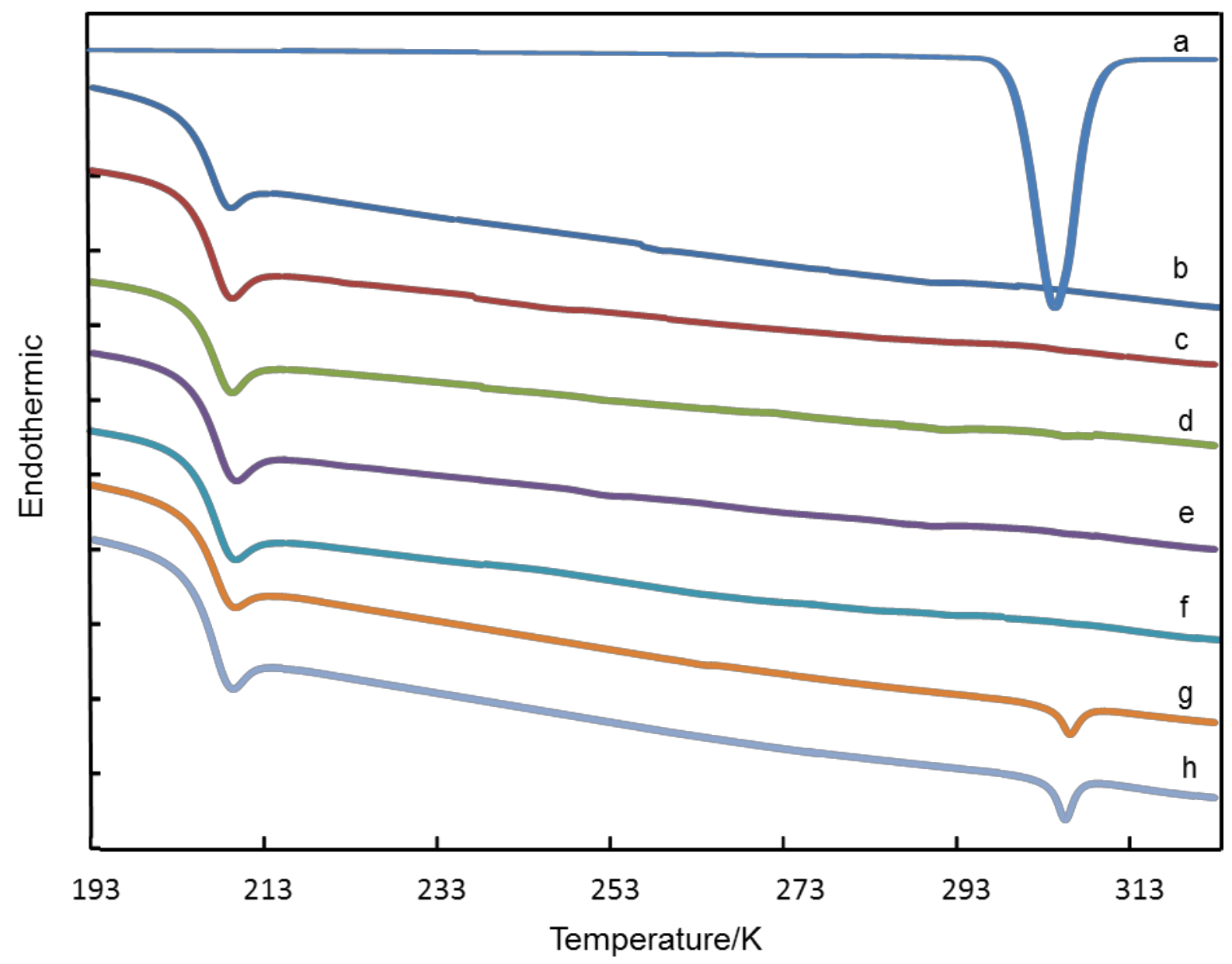

Figure 6: DSC thermograms for (a) PSMA (b) DPNR and (c) DPNR-graft-PSMA-0.25 (d) DPNR-graft-PSMA-0.5, (e) DPNR-graft-PSMA-0.75, (f) DPNR-graft-PSMA-1.0 and (g) DPNR-graft-PSMA-1.5 (h) DPNR-graft-PSMA-2.0

The DSC thermograms for the DPNR, PSMA and graft-copolymers are shown in Figure 6. The melting endothermic peak for the neat PSMA was a single and sharp peak, with the top was determined as the melting temperature, $T_{m}$. The melting peak was attributed to the melting of crystals of the stearyl groups, since the $T_{m}$ of PSMA was $304.1 \mathrm{~K}$ [30]. As for the graftcopolymers, the melting peak appeared to be significant for the DPNR-graft-PSMA-1.5 and 
DPNR-graft-PSMA-2.0, while it appeared to be weak for the DPNR-graft-PSMA-0.25, DPNRgraft-PSMA-0.5, DPNR-graft-PSMA-0.75 and DPNR-graft-PSMA-1.0.

The $T_{m}$ and degree of crystallinity (w/w\%) of the PSMA fraction in 100\% PSMA, $X_{C}$, PSMA and in the graft-copolymer, $X_{C, G C}$ are tabulated in Table 5. The $X_{C \text {, PSMA }}$ was calculated based on the ratio of the heat of fusion of the crystalline PSMA fraction to that of the neat PSMA, which was taken as $142.1 \mathrm{~J} / \mathrm{g}(48.1 \mathrm{~kJ} / \mathrm{mol})$ [31], by assuming $100 \%$ crystallization of the $18 \mathrm{CH}_{2}$, as expressed by the following equation (4):

$$
X_{C, P S M A}(w / w \%)=\frac{\Delta H_{(P S M A)}}{\Delta H_{(\text {neat } P S M A)}} x 100
$$

In the graft-copolymer of PSMA with a weight fraction, $W(\mathrm{w} / \mathrm{w})$, the $X_{C, G C}$ was calculated by the following equation (5):

$$
X_{C, G C}(w / w \%)=\frac{X_{C, G C}}{W} \times 100
$$

The $T_{m}$ increased as the SMA concentration increased and so did the degree of crystallinity (w/w\%). The $T_{m}$ increased positively from $304 \mathrm{~K}$ (neat PSMA) to $306.2 \mathrm{~K}$ (DPNR-

graft-PSMA-3.3-2.0). Furthermore, the $X_{C, \text { PSMA }}$ and $X_{C, G C}$ in the DPNR-graft-PSMA-1.5 were the highest, at about $7.41 \mathrm{w} / \mathrm{w} \%$ and $0.5 \mathrm{w} / \mathrm{w} \%$, respectively. The increase in $T_{m}, X_{C, \text { PSMA }}$ and $X_{C}$, GC may be explained to be due to the increase in the PSMA fractions in the DPNR. Thus, the crystallinity of the PSMA fraction in the DPNR is expected to contribute to the mechanical properties of the rubber, i.e. the tensile properties [32].

\subsection{Tensile strength}

Figure 7 shows the plots of the stress versus strain for (a) DPNR, (b) DPNR-graftPSMA-0.25 and (c) DPNR-graft-PSMA-1.5, respectively. The stress for the DPNR-graft- 
PSMA-0.25 and DPNR-graft-PSMA-1.5 increased abruptly at a strain of 3 compared to that of DPNR. The increase in the stress at a strain of 3 was dependent on the SMA unit content, whereby the value of the stress at a strain of 3 for the DPNR-graft-PSMA-1.5 was higher than for the DPNR-graft-PSMA-0.25. As reported previously, the increase in the stress at a strain 3 was attributed to the crystallization of the rubber on straining [32]. The crystallization started at strain 3, and then it is abruptly increase and noticeable at strain 5 because the crystallization may continue at this strain. Thus, the abrupt increase in the DPNR-graft-PSMA-1.5 and DPNR-graftPSMA-0.25 may be explained to be due to the strain-induced crystallization promoted by the nucleating effect of the linked SMA. Furthermore, the value of the stress at break for the DPNRgraft-PSMA-1.5 was remarkably high, i.e. $13 \mathrm{MPa}$, as compared to $7 \mathrm{MPa}$ for the DPNR-graftPSMA-0.25, and 5 MPa for DPNR. In contrast, the strain at break for the DPNR-graft-PSMA1.5 was the lowest among the samples. In previous studies for polystyrene-grafted DPNR (DPNR-graft-PS), it was found that the stress and strain at break were related to the grafting efficiency [33]. However, in the present study for DPNR-graft-PSMA, the stress at break was significantly improved, despite the low grafting efficiency. This may strongly indicate that the linked SMA plays an important role in the strain-induced crystallization, which resulted in the outstanding mechanical properties. 
Table 5: Thermal behaviour for PSMA, DPNR and graft-copolymers

\begin{tabular}{|c|c|c|c|c|c|c|c|c|c|}
\hline & $\begin{array}{c}T_{g(\mathrm{DPNR})} \\
(\mathrm{K})\end{array}$ & $\begin{array}{c}T_{m(\mathrm{PSMA})} \\
(\mathrm{K})\end{array}$ & $\begin{array}{c}\text { Amount } \\
\text { of PSMA } \\
\text { (mmol/kg- } \\
\text { rubber) }\end{array}$ & $\begin{array}{c}\text { Amount } \\
\text { of PSMA } \\
\text { (g/kg- } \\
\text { rubber) }\end{array}$ & $\begin{array}{l}\text { Weight } \\
\text { fraction, } \\
W(\mathrm{w} / \mathrm{w})\end{array}$ & $\begin{array}{c}\Delta \mathrm{H}_{\text {(Total) }} \\
(\mathrm{J} / \mathrm{g})\end{array}$ & $\begin{array}{c}\Delta \mathrm{H}_{(\mathrm{PSMA})} \\
(\mathrm{J} / \mathrm{g})\end{array}$ & $\begin{array}{c}\text { Degree of } \\
\text { crystallinity } \\
\text { (w/w\%), } \\
X_{C, \text { PSMA }} \\
\text { (in } 100 \% \\
\text { PSMA) }\end{array}$ & $\begin{array}{c}\text { Degree of } \\
\text { crystallinity } \\
\text { (w/w\%), } \\
X_{C, G C} \\
\text { (in graft- } \\
\text { copolymer) }\end{array}$ \\
\hline DPNR & 205.6 & - & - & - & & - & - & - & - \\
\hline PSMA & - & 304.1 & - & - & - & 44.4 & - & - & - \\
\hline DPNR-graft-PSMA-0.25 & 205.6 & 304.8 & 98.92 & 33.49 & 0.03 & 0.09 & 2.78 & 1.95 & 0.06 \\
\hline DPNR-graft-PSMA-0.5 & 205.7 & 305.7 & 53.93 & 18.26 & 0.02 & 0.03 & 1.67 & 1.18 & 0.02 \\
\hline DPNR-graft-PSMA-0.75 & 205.7 & 306.0 & 48.99 & 16.58 & 0.02 & 0.04 & 2.45 & 1.73 & 0.03 \\
\hline DPNR-graft-PSMA-1.0 & 205.6 & 306.0 & 117.28 & 39.70 & 0.04 & 0.06 & 1.57 & 1.11 & 0.04 \\
\hline DPNR-graft-PSMA-1.5 & 205.6 & 306.2 & 194.37 & 65.80 & 0.06 & 0.65 & 10.53 & 7.41 & 0.46 \\
\hline DPNR-graft-PSMA-2.0 & 204.9 & 306.2 & 219.89 & 74.44 & 0.07 & 0.52 & 7.50 & 5.28 & 0.37 \\
\hline
\end{tabular}



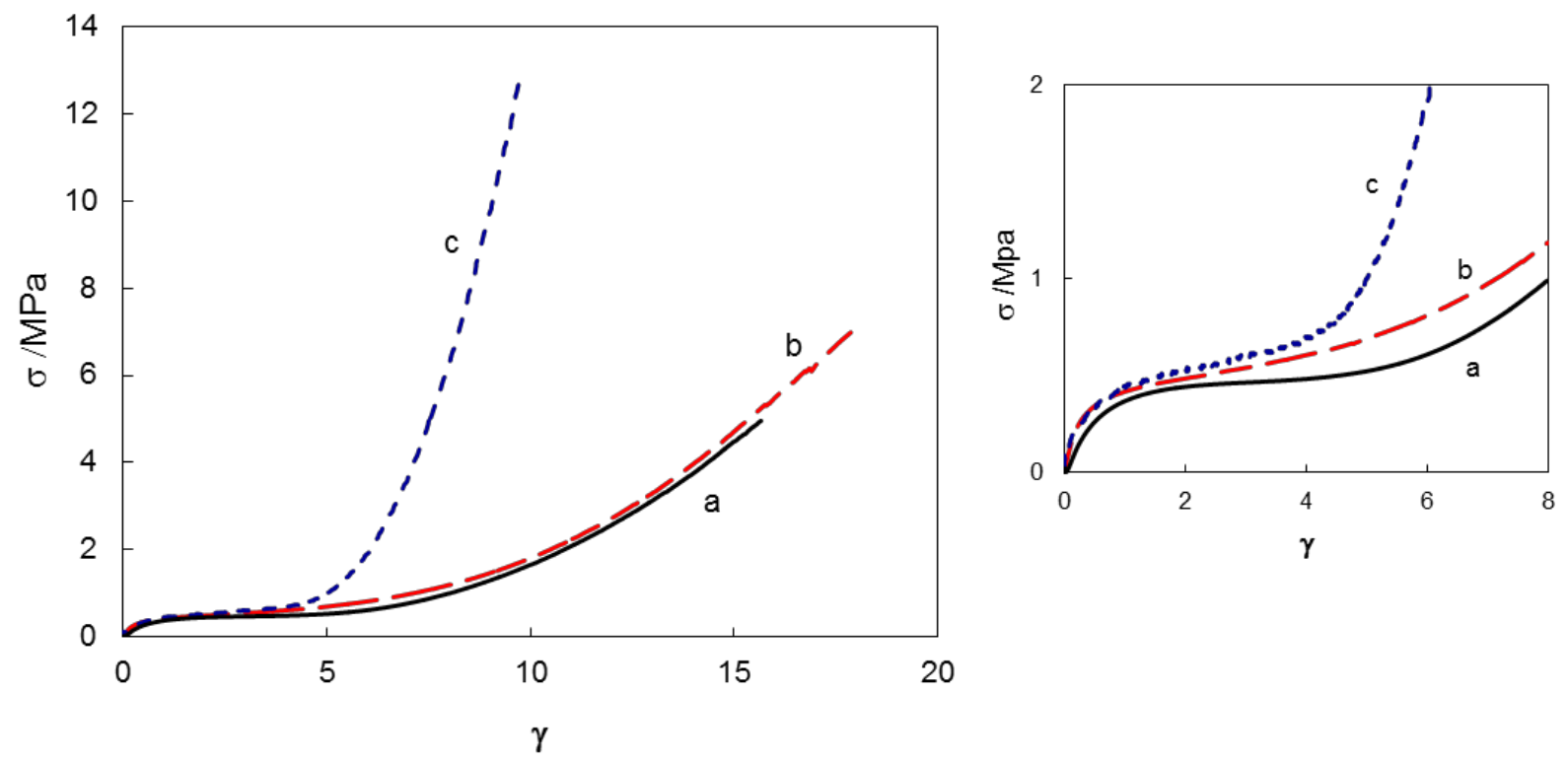

Figure 7: Stress-strain curves for (a) DPNR, (b) DPNR-graft-PSMA-0.25, and (c) DPNR-graftPSMA-1.5.

3.6 Morphology of DPNR-graft-PSMA by TEM

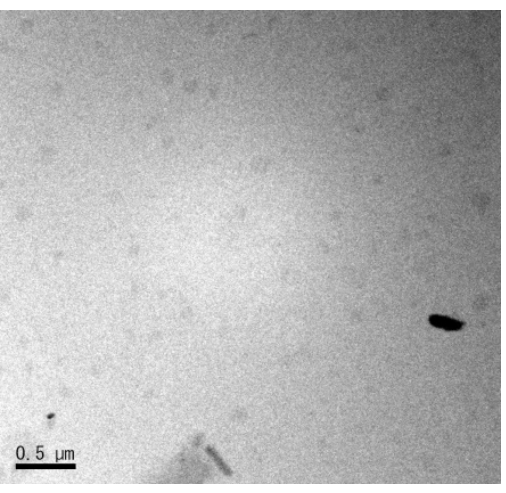

(a)

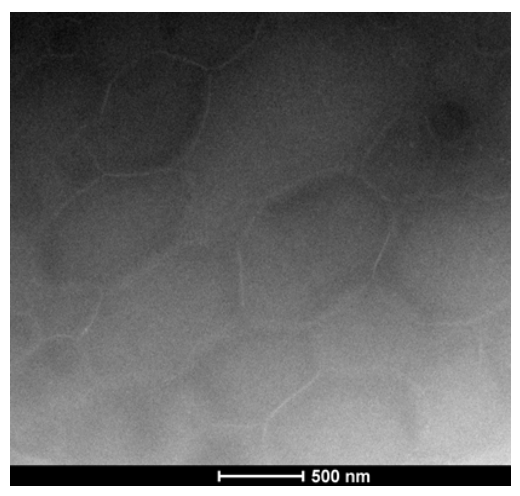

(b)

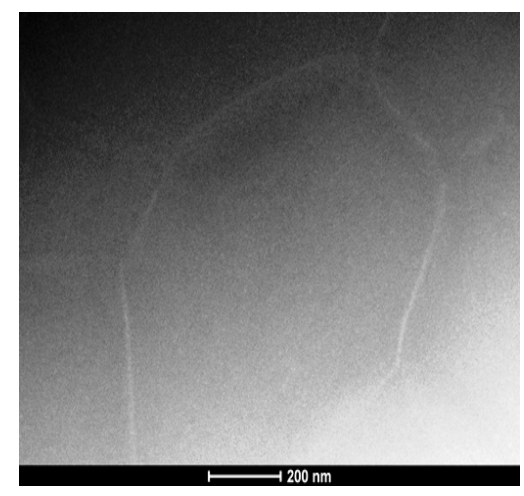

(c)

Figure 8: TEM images for (a) DPNR film (5000x magnification) (b) DPNR-graft-PSMA (5000x magnification) (c) expanded TEM image for DPNR-graft-PSMA (20000x magnification).

Figure 8 shows the TEM images for DPNR and DPNR-graft-PSMA-1.5. For DPNR (control), the bright domain represents the DPNR particles; the dark domain represents the remaining non-rubber components. Whilst, for DPNR-graft-PSMA-1.5, the shades of the 
domains were contrast, in which, the dark domain represents the DPNR particles and bright domain represents PSMA. The dark DPNR particles of about $1 \mu \mathrm{m}$ in average were well dispersed in the bright PSMA matrix of about 20-30 nm in thickness. The morphology showed that the nanomatrix structure is formed by graft-copolymerization of SMA onto DPNR in latex stage. Hence, the nanomatrix structure as well as the nucleating effect of PSMA may contribute to the outstanding mechanical properties of natural rubber.

\section{Conclusion}

DPNR-graft-PSMA was prepared by the graft-copolymerization of SMA onto DPNR in latex stage in the presence of TBHP/TEPA as an initiator. The highest conversion of $95 \mathrm{~mol} \%$ and grafting efficiency of 62 mol\% were achieved for DPNR-graft-PSMA-1.5 under the optimal conditions of $3.3 \times 10^{-2} \mathrm{~mol} / \mathrm{kg}$-rubber of initiator, $1.5 \mathrm{~mol} / \mathrm{kg}$-rubber of SMA and $30 \mathrm{w} / \mathrm{w} \%$ of DRC. The SMA unit content and $T_{m}$ were $194 \mathrm{mmol} / \mathrm{kg}$-rubber and $306.3 \mathrm{~K}$, respectively. The degree of crystallinity (w/w\%) of the PSMA fraction in the graft-copolymer, i.e. DPNR-graftPSMA-1.5, was the highest at about $0.5 \mathrm{w} / \mathrm{w} \%$. Based on TEM images, the nanomatrix structure was formed for DPNR-graft-PSMA, whereby the DPNR particles were dispersed in the nanometer thickness of PSMA matrix. The highest stress at break of 13 MPa was achieved for DPNR-graft-PSMA-1.5, which was about three times as high as that of DPNR. The abrupt increase in the stress at a strain of 3 may be explained to be due to the nucleating effect of the grafted PSMA, i.e. the crystallizable stearyl groups. It is, therefore, concluded that the straininduced crystallization of the DPNR-graft-PSMA is promoted by the effect of the PSMA. 


\section{Acknowledgement}

This work was supported in part by a Grant-in-Aid (26620176) for Challenging Exploratory

Research and Grant-in-Aid (25288098) for Scientific Research (B) from Japan Society for the Promotion of Science and JST-JICA SATREPS.

\section{References}

1. Malta, V.; Celotti, G.; Zannetti, R.; Martelli, A.F, J. Chem. Soc. B, 1971, 548.

2. Sydow, E. V. Acta Cryst., 1955, 8, 557.

3. Natta, G.; Corradini, P. Angew. Chemie., 1956, 68, 615.

4. Goto, M.; Asada, E. Bull. Chem. Soc. Jpn, 1978, 51, 2456.

5. Mitchell, J. C.; Meier, D. J.; J. Polym. Sci. A-2 Polym. Phys., 1968, 6, 1689.

6. Tosaka, M.; Senoo, K.; Sato, K.; Noda, M.; Ohta, N. Polymer, 2012, 53, 864.

7. Kawazura, T.; Kawahara, S.; Isono, Y.; Rubber Chem. Technol., 2003, 76, 1164.

8. Kawazura, T.; Kawahara, S.; Isono, Y. J. Appl. Polym. Sci, 2005, 98, 613.

9. Gent, A.N. Trans Inst. Rubber Ind., 1954, 30, 139.

10. Kawahara, S.; Nishiyama,N.; Kakubo, T.; Tanaka, Y. Rubber Chem. Technol., 1996, 69, 600

11. Burfield, D.R. Polymer, 1984, 25, 1823.

12. Kawahara, S.; Kakubo, T.; Sakdapipanich, J.T.; Isono, Y.; Tanaka, Y. Polymer, 2000, 41, 7483.

13. Kawahara, S.; Chaikumpollert, O.; Akabori, K.; Yamamoto, Y. Polym. Adv. Technol., 2011, 22, 2665.

14. Wong, A.K.; Campbell, D.S.; Tinker, A.J. Polymer, 1987, 28, 2157.

15. Wong, A.K.; Campbell, D.S.; Tinker, A.J. Polymer, 1987, 28, 2161. 
16. Odian, G. Radical chain polymerization, Principles of Polymerization, Fourth Edition, 2004, 198, Wiley, New Jersey.

17. Zhou, M.H.; Hoang, T.; Kim, I.G.; Ha, C.S.; Cho, W.J. J. Appl. Polym. Sci., 2001, 79, 2464.

18. Kawahara, S.; Klinklai, W.; Kuroda, H.; Isono, Y. Polym. Adv. Technol., 2004, 15, 181.

19. Klinklai, W.; Saito, T.; Kawahara, S.; Tashiro, K.; Suzuki, Y.; Sakdapipanich, J.T.; Isono, Y. J. Appl. Polym. Sci., 2004, 93, 555.

20. Pukkate, N.; Kitai, T.; Yamamoto, Y.; Kawazura, T.; Sakdapipanich, J.; Kawahara, S. Eur. Polym. J., 2007, 43, 3208.

21. Kawahara, S.; Kawazura, T.; Sawada, T.; Isono, Y. Polymer, 2003, 44, 4527.

22. Yusof, N.H.; Kawahara, S.; Mazam, M. S. J. Rubb. Res., 2008, 11, 97.

23. Prukkaewkanjana, K.; Kawahara, S.; Sakdapipanich, J. Adv. Mater. Res., 2014, 844, 365.

24. Kawahara, S.; Yusof, N.H.; Noguchi, K.; Kosugi, K.; Yamamoto, Y. Polymer, 2014, 55, 5024.

25. Yusof, N.H.; Noguchi, K.; Fukuhara, L.; Yamamoto, Y.; Kawahara, S. Colloid. Polym. Sci., 2015, 293, 2249.

26. Fukushima, Y.; Kawahara, S.; Tanaka, Y. J. Rubb. Res., 1998, 1, 154.

27. Kochthongrasamee, T.; Prasassarakich, P.; Kiatkamjornwong, S. J. Appl. Polym. Sci., 2006, 101, 4, 2587.

28. Sakdapipanich, J.T.; Rojruthai, P. Molecular structure of natural rubber and its characteristics based on recent evidence, Chapter 3, Biotechnology-molecular studies and novel applications for improved quality of human life, 2012, 213, InTech Croatia.

29. Shang, S.; Huang, S.J.; Weiss. R.A. ACS Polymer Preprints, 2007, 48, 2, 871.

30. Shang, S.; Huang, S. J.; Weiss, R.A. Polymer, 2009, 50, 3119. 
31. Inomata, K.; Sakamaki, Y.; Nose, T.; Sasaki, S. Polym. J., 1996, 28, 986.

32. Kawahara, S.; Kakubo, T.; Nishiyama, N.; Tanaka, T.; Isono, Y.; Sakdapipanich, J.T. J. Polym. Sc., 2000, 78, 1510.

33. Suksawad, P.; Yamamoto, Y.; Kawahara, S., Eur. Polym. J., 2011, 47, 330.

34. Bandrup, J.; Immergut, E.H.; Grulke, E.A. Polymer Handbook, Section II, Chapter 1, Fourth Edition, 1999, John Wiley \& Sons, Inc.,.

35. Joseph C. S. Polymeric Materials Encyclopedia, Twelve Volume Set, pg 4929, 1996, CRC Press. 

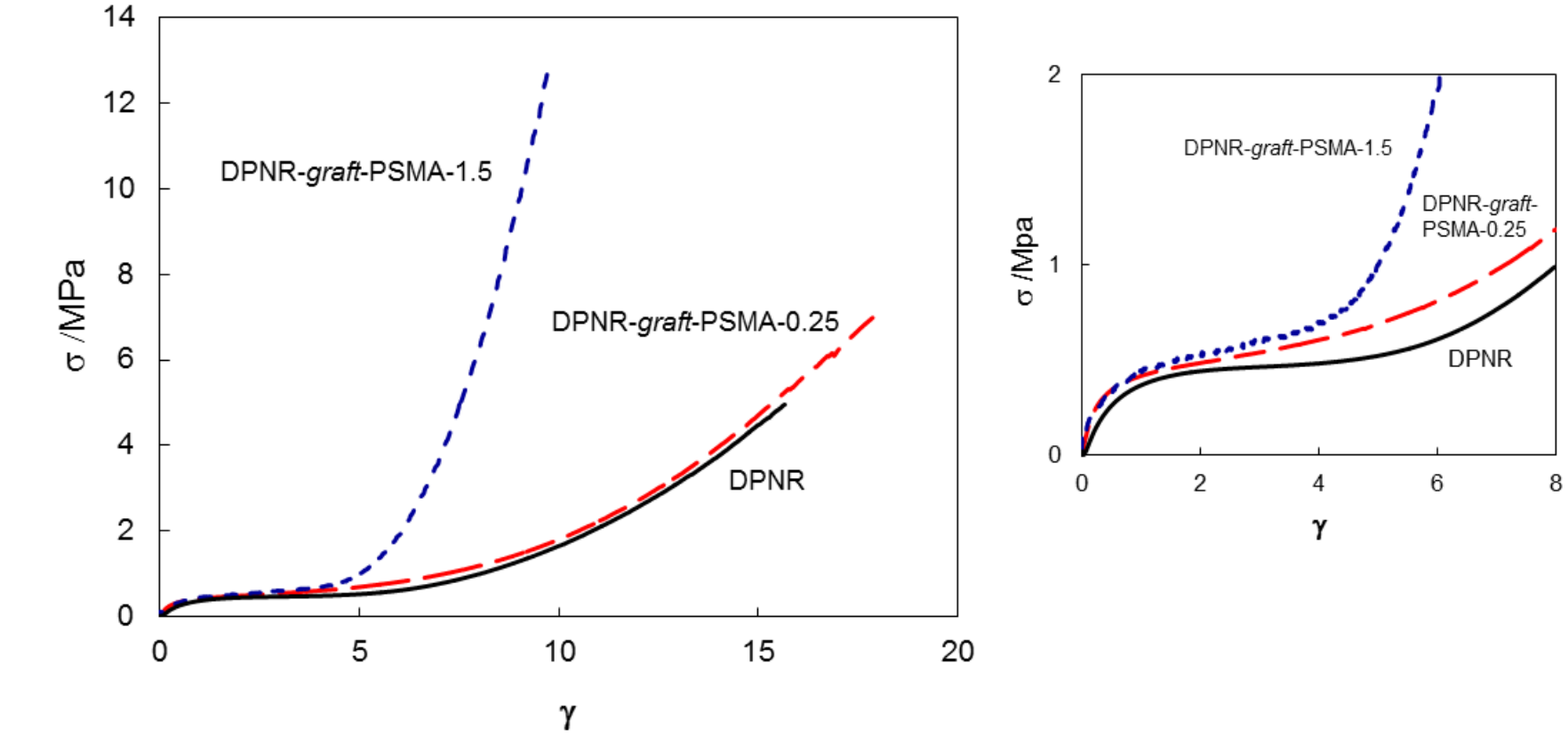